\title{
CREATING AND SUSTAINING EFFECTIVE ALNS
}

\author{
Starr Roxanne Hiltz \\ Distinguished Professor, Information Systems Department \\ New Jersey Institute of Technology
}

\begin{abstract}
Pedagogy, software, and student motivation form an interactive system that either supports the emergence and growth of a vibrant online learning community, or does not. This article briefly reviews some of the research that has been carried out at NJIT and elsewhere over the last 25 years that supports this view. It starts with collaborative learning pedagogy, since this is the foundation of a successful learning network.
\end{abstract}

\section{INTRODUCTION}

Whenever the quality of online courses is discussed, some faculty members give glowing accounts of active dialogue and better communication with students than in face to face courses. Others counter that they taught or observed an online class where there was little or no interaction, just "no new items waiting" day after day. Of course, there is great variability in the liveliness of traditional classrooms and the quality of the courses, too, but it seems even more marked in the virtual classroom. We know from over 30 empirical studies comparing the effectiveness of ALN (asynchronous learning networks) and face to face (f2f) courses that overall, ALN courses are on the average, as effective or more effective than FfF ones, but that there is much more variability within modes than between them [1,2]. Though there are many, many variables that contribute to and help to explain the effectiveness of courses taught using the ALN paradigm [3], the most important is the pedagogy and the presence that the instructor brings to the course. The instructor's success can be greatly aided, however, by a software platform that supports collaborative learning and allows forms of interaction that would be difficult to achieve in a traditional classroom, thus capitalizing on the power of computer-mediated communication. And of course, what occurs online is also affected by what the students bring to the course, especially their motivation in regard to the course.

\section{PEDAGOGY: ESTABLISHING “SWIFT TRUST” AS THE FOUNDATION FOR COLLABORATIVE LEARNING}

There is a significant link between instructor activity and the development of virtual learning communities in online courses [4,5]. The most effective online teachers establish communication and trust early and quickly, in the first week of the course [6]. Team members must perceive the instructor's presence as soon as they enter the course [7]. Effective instructors initially provide students with clear course introductory information and personal introductions that set the climate for warmth and responsiveness. By "swiftly" replying to each student's initial comments, and modeling constructive responses, the most effective instructors provide students with a sense that there really is a professor at the other end of the communication link who reinforces responsive behavior in students.

How do good instructors develop a positive social atmosphere online? They model solidarity, congeniality, and affiliation. This means that the leader/teacher explicitly gives praise, encouragement, or approval for the efforts of the team members/students, when they are in fact meeting expectations. If someone is not meeting expectations, this is handled by private email rather than public scolding. Good 
online teachers also reinforce predictable patterns in communication and action. They give students carefully structured activities and regular responses and feedback. They frequently ask students to expand or clarify task information [6].

\section{PEDAGOGY: COLLABORATIVE LEARNING}

The pedagogical assumption that students learn by constructing knowledge through group interaction is the theoretical foundation of ALN [8]. Collaborative learning is based upon a model that treats the student as an active participant in group activities. The learner becomes actively involved in constructing knowledge by applying concepts to problems, and/or formulating ideas into words, thus knowledge is built upon through reactions and responses of others [9, 10]. In other words, learning is not only active but also interactive. Active involvement can take place through communication with the instructor, or with peers. Collaborative learning refers to instructional methods that encourage students to work together on academic tasks. It involves interpersonal processes as groups of students work together to complete an academic problem-solving task that promotes learning.

An example of collaborative learning is the online seminar in which the students become the teachers. Individuals or small groups of students are responsible for selecting topics; reading material not assigned to the rest of the class; preparing written summaries of the most important ideas in the material, including links to resources on the Web; and leading a discussion on the topic. Another example is the collaborative exam where students are required to identify key concepts or skills in each module of the course, to construct exam questions, and to answer each other's questions. Students are thus made partners in deciding what course material is important to know [11]. Other examples of collaborative learning strategies suited to the ALN environment include debates, group projects, case study discussions, simulation and role-playing exercises, sharing of solutions to different homework problems, and collaborative composition of essays, stories, or research plans.

\section{GENERATING ACTIVE PARTICIPATION WITH APPROPRIATE SOFTWARE}

Appropriate software as well as appropriate pedagogy is needed to support the communication necessary to build and sustain a learning community. At a minimum, one needs a computer conferencing system that provides a self-organizing structure via separate discussions for each topic or activity in a course, and within each discussion organizes the dialogue into threads with roots and replies. The platform also needs to support attachments or incorporation of digital multi-media material, such as digital audio or video clips, or text with HTML markups and links. There are many other desirable features, and many of them are not included in any systems commercially available [12].

Among the types of software beneficial for creating active participation and supporting interactivity are quiz routines designed for self testing and mastery learning. These routines are available on many ALN platforms, and may include diagnostic feedback and multimedia simulations, such as an online laboratory for organic chemistry or an electronics circuits course. Such software supports interaction between the student and a program, rather than among students and faculty, and the active, tailored learning and feedback enhance learning. For example, students at Michigan State [13] who took a class using ALN in combination with a computer assisted quiz program (with immediate diagnostic feedback) received midterm grades $20 \%$ higher compared to students in traditional classes.

An example of a feature that is unique to the online environment is the "pen name" or "handle," as well as 
anonymity, that some systems provide as an option for posting entries in a discussion. Unlike anonymity, the pen name allows a student to adopt a consistent persona, such as "a stockholder" for a business case study. When using pen names or anonymity, neither of which is available f2f except perhaps by donning a mask and costume, learning through role playing can be enhanced.

The Virtual Classroom ${ }^{\circledR}$ system had a "question-response activity" that required each student to answer a question for discussion before being able to see the answers. As soon as a student did answer, the replies of other students became viewable and could be responded to, but prior to this, each student thought independently, rather than being influenced by prior answers from other students. This is an example of a structure that is pedagogically useful, but not available in current commercial systems. There are undoubtedly many other structures and tools that would be very useful for supporting ALN courses that will appear in new software platforms in the years to come.

\section{STUDENT CHARACTERISTICS: MOTIVATION IS THE KEY}

Students who are motivated, self-directed and confident about having the computer skills necessary to use the technology are most likely to thrive in the ALN environment. Often these are students who are older than traditional on-campus undergraduates. One aspect of motivation is the reason for taking an online course. In a study at SUNY, Frederickson et al. [14] found that students who reported that they were taking the course because it was not offered on campus (and thus they had no choice of mode), also reported significantly lower levels of learning than students who chose to take the course online because of family responsibilities or because of a conflict with their personal schedules.

While examinations of student characteristics may allow us to understand who is most likely to succeed in online learning environments, the larger and more important issues may be about how we can help most or all students seeking online education to succeed. We especially need to know more about how to support weaker students - online environments pose additional challenges and opportunities in this regard. We need additional inquiry to provide "best practices" guidelines in at least three areas: student support, faculty support and institutional alignment for online learning [15].

\section{SUMMARY AND CONCLUSION}

Pedagogy, software, and student motivation form a dynamic system. If the software is inadequate, collaborative learning will be difficult to sustain; for instance, trying to use email will not support rich knowledge building exchanges on multiple simultaneous topics for a medium to large class. The behavior of the instructor, especially at the beginning of the course, can increase or decrease student motivation, as can the ease of use, functionality, and reliability of the software. In turn, high levels of student motivation lead to the high levels of participation that make collaborative learning an engaging and effective process.

\section{REFERENCES}

1. Hiltz, S. R. The Virtual Classroom: Learning Without Limits Via Computer Networks. Norwood, NJ: Ablex Publishing (Human-Computer Interaction Series), 1994.

2. Fjermestad, J., S. R. Hiltz, and Y. Zhang. Effectiveness for Students: Comparisons of "In-seat" and ALN Courses. In: Hiltz, S. R. and R. Goldman (Eds.), Learning Together Online: Research on Asynchronous Learning Networks, 39-80. Mahwah, NJ: Erlbaum, 2005. 
3. Benbunan-Fich, R., S. R. Hiltz, and L. Harasim. The Online Interaction Learning Model: An Integrated Theoretical Framework for Learning Networks. In: Hiltz, S.R. and R. Goldman (Eds.), Learning Together Online: Research on Asynchronous Learning Networks, 19-37. Mahwah, NJ: Erlbaum, 2005.

4. Rovai, A. P. A preliminary look at the structural differences of higher education classroom communities in traditional and ALN courses. Journal of Asynchronous Learning Networks 6 (1): 41-56, 2002.

5. Swan, K. and P. Shea. The Development of Virtual Learning Communities. In: Hiltz, S.R. and R. Goldman (Eds.), Learning Together Online: Research on Asynchronous Learning Networks, 239-260. Mahwah NJ: Erlbaum, 2005.

6. Coppola, N. W., S. R. Hiltz, and N. Rotter. Building trust in virtual teams. IEEE Transactions on Professional Communication 47 (2): 95-104, June 2004.

7. Garrison, D. R. Cognitive Presence for Effective Asynchronous Online Learning: The Role of Reflective Inquiry, Self-direction and Metacognition. Paper presented at the Fourth Annual Sloan ALN Workshop, Boltons Landing NY, 2002.

8. Harasim, L., S. R. Hiltz, L. Teles, \& M. Turoff. Learning Networks: A Field Guide to Teaching and Learning Online. Cambridge, MA: MIT Press, 1995.

9. Bouton, C., \& R. Y. Garth. Learning in Groups. San Francisco, CA: Jossey-Bass, Inc., 1983.

10. Alavi, M. Computer-Mediated Collaborative Learning: An Empirical Evaluation. MIS Quarterly 18 (2): 150-174, 1994.

11. Shen, J. Collaborative Examinations in Asynchronous Learning Networks. Ph.D. dissertation. Information Systems Department, NJIT, May 2005.

12. Turoff, M. and S. R. Hiltz. Software Design and the Future of the Virtual Classroom. Journal of Information Technology for Teacher Education 4 (2): 197-215, 1995.

13. Thoennessen, M., E. Kashy, Y. Tsai, and N. E. Davis. Impacts of Asynchronous Learning Networks in Large Lecture Classes. Group Decision and Negotiation 8: 371-384, 1999.

14. Frederickson, E., A. Pickett, P. Shea, W. Pelz, \& K. Swan. Student satisfaction and perceived learning with online courses: Principles and examples from the SUNY Learning Network. Journal of Asynchronous Learning Networks 4 (2): 2000.

15. Hiltz, S. R. and P. Shea. The Student in the Online Classroom. In: Hiltz, S. R. and R. Goldman (Eds.). Learning Together Online: Research on Asynchronous Learning Networks, 145-168. Mahwah, NJ: Erlbaum, 2005.

\section{ABOUT THE AUTHOR}

Starr Roxanne Hiltz is currently a Distinguished Professor in the Information Systems Department, College of Computing Sciences, New Jersey Institute of Technology. She is most proud and grateful for the 2004 Sloan-C award for "Most Outstanding Achievement in Online Teaching and Learning by an Individual.” The Network Nation: Human Communication via Computer, co-authored with Murray Turoff in 1978, described the technical and social possibilities for what has become the Internet and the World Wide Web; this book received an award from the Association of American Publishers for the Best Technical-Scientific Publication of the year. Shortly after, while a visiting fellow at Princeton University sitting in on a seminar on the sociology of architecture, she conceived the possibility of an online "virtual classroom" environment; then designed, implemented, and studied the first version of such a system in 1986-88, and trademarked the name for NJIT. She is the recipient of the Electronic Frontier Foundation's "Pioneer" award, 1994, for "significant and influential contributions to computer-based communications and to the empowerment of individuals in using computers." In 2000, she conceived of and created the 
"WebCenter for Learning Networks Effectiveness Research" (www.ALNResearch.org), an online knowledge repository and research community to improve the quality, quantity, and dissemination of research on online courses, which is supported by the Alfred P. Sloan Foundation. The 2005 Rudolph J. Joenk Jr. Award for best article in IEEE Transactions on Professional Communication was awarded for Coppola, Hiltz, and Rotter (2004), Building Trust in Virtual Teams. Among her current projects is the implementation and study of SmartCampus at NJIT. 